\title{
Evaluation of the effects of food on
}

\section{levodropropizine controlled-release tablet and its pharmacokinetic profile in comparison to that of immediate-release tablet}

This article was published in the following Dove Press journal:

Drug Design, Development and Therapy

Soyoung Lee, ${ }^{1, *}$ Kyu-Yeol $\mathrm{Nam},{ }^{2,3, *}$ Jaeseong Oh, SeungHwan Lee,' Sang-Min Cho, ${ }^{3}$ Youn-Woong Choi, ${ }^{3}$ Joo-Youn Cho,' Beom-Jin Lee, ${ }^{2,4, *}$ Jang Hee Hong ${ }^{5, *}$

'Department of Clinical Pharmacology and Therapeutics, Seoul National University College of Medicine and Hospital, Seoul, Republic of Korea; ${ }^{2}$ College of Pharmacy, Ajou University, Suwon, Republic of Korea; ${ }^{3}$ Korea United Pharm Inc., Seoul, Republic of Korea; ${ }^{4}$ Institute of Pharmaceutical Science and Technology, Ajou University, Suwon, Republic of Korea; ${ }^{5}$ Department of Pharmacology, Chungnam National University Hospital and College of Medicine, Daejeon, Republic of Korea

*These authors contributed equally to this work

Correspondence: Jang-Hee Hong Department of Pharmacology, Chungnam National University Hospital and College of Medicine, 266 munhwa-ro, Jung-gu, Daejeon 35015, Republic of Korea Tel +82 422806940

Fax +82422806947

Email boniii@cnu.ac.kr

Beom-Jin Lee

College of Pharmacy, Ajou University, Institute of Pharmaceutical Science and Technology, Ajou University, 206 Worldcup-ro, Yeongtong-gu, Suwon 16499, Republic of Korea Tel +82 3I 2I 93502

Fax +82312123653

Email bjl@ajou.ac.kr
Background: Levodropropizine is a non-opioid antitussive agent that inhibits cough reflex by reducing the release of sensory peptide in the peripheral region. To improve patients' compliance, a controlled-release (CR) tablet is under development. The aim of this study was to compare the pharmacokinetic (PK) profiles of the CR and immediate-release (IR) tablets of levodropropizine. In addition, the effect of food on the PK properties of levodropropizine CR tablet in healthy subjects was evaluated.

Subjects and methods: A randomized, open-label, multiple-dose, three-treatment, threeperiod, six-sequence, crossover study was conducted on 47 healthy subjects. All subjects were randomly assigned to one of the six sequences, which involve combinations of the following three treatments: levodropropizine IR $60 \mathrm{mg}$ three times in the fasted state (R), levodropropizine CR $90 \mathrm{mg}$ two times in the fasted state (T), and levodropropizine CR $90 \mathrm{mg}$ two times in the fed state (TF). Serial blood samples were collected up to $24 \mathrm{~h}$ after the first dose. Tolerability was assessed based on the vital signs, adverse events (AEs), and clinical laboratory tests.

Results: Levodropropizine CR showed lower maximum drug concentration $\left(C_{\max }\right)$ and similar total exposure compared to levodropropizine IR. The geometric mean ratios (GMRs) $(90 \%$ confidence intervals [CIs]) of T to $\mathrm{R}$ for the $C_{\max }$ and area under the concentration-time curve from the 0 to $24 \mathrm{~h}$ time points $\left(\mathrm{AUC}_{0-24 \mathrm{~h}}\right)$ were $0.80(0.75-0.85)$ and $0.89(0.86-0.93)$, respectively. In the fed group, levodropropizine $\mathrm{CR}$ showed exposure similar to that in the fasted group. The GMRs (90\% CIs) of TF to T for the $C_{\max }$ and $\mathrm{AUC}_{0-24 \mathrm{~h}}$ were $0.90(0.85-0.97)$ and $1.10(1.05-1.14)$, respectively. No serious AEs occurred with both levodropropizine CR and IR tablets.

Conclusion: Total systemic exposure for levodropropizine was similar in subjects receiving the CR and IR formulations in terms of the AUC. Although food delayed the absorption of levodropropizine CR, systemic exposure was not affected.

Keywords: pharmacokinetics, controlled-release, immediate-release, food effect

\section{Introduction}

Cough is a respiratory defense mechanism to protect our body from external materials, such as dust and pathogens. However, persistent and uncontrollable cough can affect the patients' quality of life by inducing nausea and sleep disturbance. ${ }^{1}$ To relieve cough, levodropropizine is one of the therapeutic options used to treat acute and chronic bronchitis. ${ }^{2}$ Levodropropizine is a peripherally acting, non-opioid antitussive agent, which inhibits the cough reflex by reducing the release of sensory peptide in the peripheral region and suppresses the afferent pathway of pulmonary. ${ }^{3-5}$ It has 
comparable efficacy and less central sedative adverse effects compared to the centrally acting antitussives. ${ }^{1}$ Levodropropizine has been approved in some Asian and European countries and has been widely used for adults and children older than 2 years in Republic of Korea.

Levodropropizine is rapidly absorbed into the gastrointestinal tract, with time required to reach the maximum drug concentration $\left(T_{\max }\right)$ ranging from 0.25 to $0.75 \mathrm{~h} .{ }^{6}$ This absorption profile is due to high bioavailability $(>75 \%)$ and rapid distribution of levodropropizine. ${ }^{7}$ The mean terminal half-life $\left(t_{1 / 2}\right)$ of levodropropizine is $2.73 \mathrm{~h}$, which suggests rapid elimination after systemic absorption. Levodropropizine has linear pharmacokinetic (PK) characteristics at doses ranging from 30 to $90 \mathrm{mg} .{ }^{8}$ The effects of food on the PK characteristics of levodropropizine have not been evaluated yet.

The food intake can change the systemic exposure of drug by altering the absorption and/or elimination of drug. For instance, food can alter either the gastric emptying time or $\mathrm{pH}$ conditions of the gastrointestinal tract, which can affect the absorption kinetics of the drug. The dietary intake can also change the elimination profile of the drug by increasing the blood flow and by stimulating the bile production. ${ }^{9,10}$ Especially in the case of a sustained release drug, it is necessary to evaluate the interaction between food and drug, since the patients are more likely to consume food during the dosing interval.

The currently available dosage forms of levodropropizine worldwide are syrup, capsule, and tablet. The levodropropizine immediate-release (IR) tablet $60 \mathrm{mg}$ is prescribed three times daily (a total daily dose of $180 \mathrm{mg}$ ) for adults. To improve the dosing convenience and patients' compliance, levodropropizine controlled-release (CR) tablet is under development by Korea United Pharm Inc. (Seoul, Republic of Korea). ${ }^{11-13}$

The aim of this study is to compare the PK profiles of CR and IR formulations of levodropropizine in the fasted state. In addition, the effects of food on the PK of levodropropizine CR formulation in healthy male subjects are evaluated.

\section{Subjects and methods Subjects}

Korean male subjects aged $20-55$ years, who were evaluated as healthy based on medical history, 12-lead electrocardiography, vital signs, physical examination, and clinical laboratory tests, were enrolled in this study. Subjects were determined healthy if they had none of the following medical histories: known hypersensitivity to levodropropizine or other antitussive agent and a history of cardiovascular, respiratory, renal, metabolic, hematologic, gastrointestinal, neurologic, psychiatric, oncologic, or hepatic disease. All subjects provided a written informed consent before participating in the study. This clinical study (Clinical Research Information Service registration number: KCT0002383) was approved by the institutional review board (IRB) of Chungnam National University Hospital (IRB number: CNUH 2011-12-019) and was conducted in accordance with the Declaration of Helsinki as implemented in the Good Clinical Practice guidelines.

\section{Study design}

A randomized, open-label, multiple-dose, three-treatment, three-period, six-sequence Williams design crossover study was conducted. The randomization was performed using the PROC PLAN procedure of SAS ${ }^{\circledR}$ software. Subjects were randomly assigned to one of the six treatment sequences, which involve combinations of the following three treatments: levodropropizine IR $60 \mathrm{mg}$ three times daily with 6-h interval in the fasted state, levodropropizine CR $90 \mathrm{mg}$ two times daily with 12-h interval in the fasted state, and levodropropizine CR $90 \mathrm{mg}$ two times daily with 12-h interval in the fed state (Figure 1). The total daily dose of levodropropizine was $180 \mathrm{mg}$ in all treatment groups. For the fasted groups, at least $10 \mathrm{~h}$ of fasted state were required prior to drug administration. For the fed group, subjects received high-fat meal (946 kcal; fat content, 35.5\%) prior to drug administration. One-week washout period was set between the different treatment periods based on the $t_{1 / 2}$ of levodropropizine. For PK analysis of levodropropizine IR, blood samples were obtained at $0,0.25,0.5,0.75,1,2$, $4,6,6.25,6.5,6.75,7,8,10,12,12.25,12.5,12.75,13$, $14,16,18$, and $24 \mathrm{~h}$ post-dose. For levodropropizine CR, serial blood samples were collected at $0,0.25,0.5,0.75,1$, $2,4,6,8,12,12.25,12.5,12.75,13,14,16,18$, and $24 \mathrm{~h}$ post-dose.

\section{Determination of levodropropizine plasma concentrations}

The blood samples were centrifuged at 3,000 rpm for $10 \mathrm{~min}$ at $4^{\circ} \mathrm{C}$, and the plasma samples were stored at $-70^{\circ} \mathrm{C}$ until assay. Plasma concentrations of levodropropizine were determined by using high-performance liquid chromatography (1260 series; Agilent Technologies, Santa Clara, CA, USA) coupled with a mass spectrometer (6410A Triple quad mass spectrometer; Agilent Technologies). The blood samples were treated with acetonitrile for precipitation of proteins, and terazosin was used as an internal standard (IS) for quantitation of levodropropizine. Levodropropizine was 


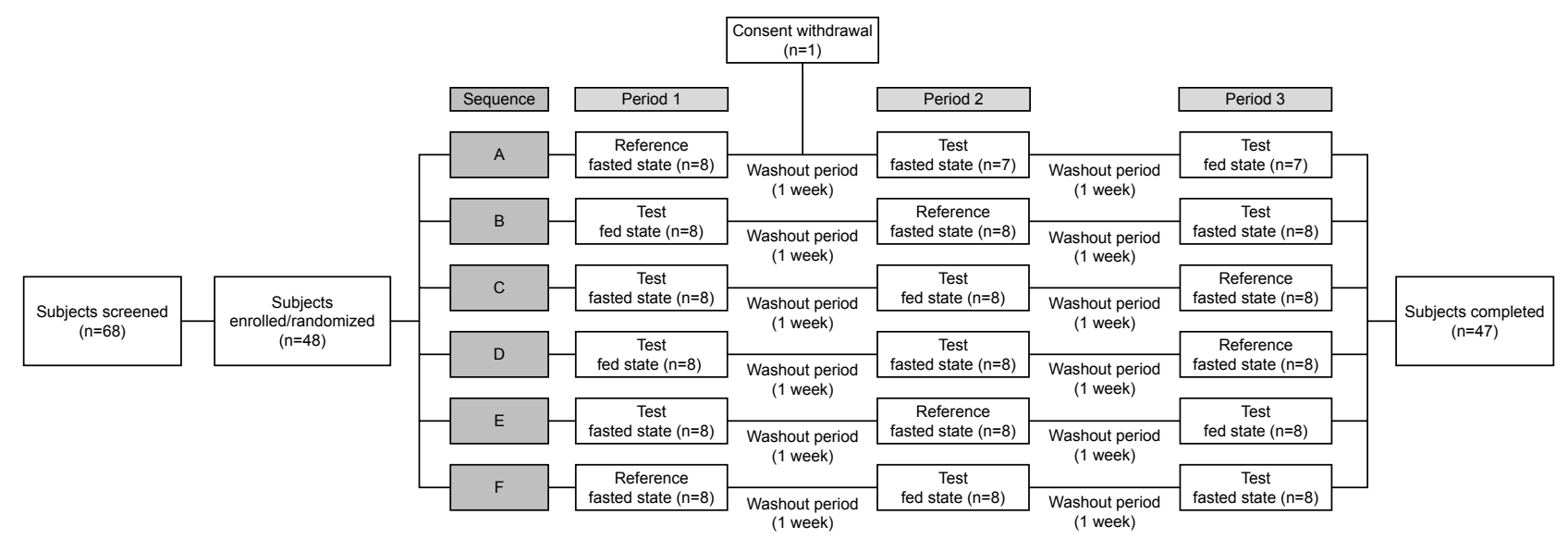

Figure I Schematic diagram of the study treatments and disposition of subjects.

Notes: Reference, levodropropizine $60 \mathrm{mg}$ IR tablet was administered three times daily with 6-h intervals in the fasted state. Test, levodropropizine $90 \mathrm{mg} C R$ tablet was administered two times with 12 -h interval in the fasted and fed states. All subjects were administered a total daily dose of $180 \mathrm{mg}$ levodropropizine during the study period. Abbreviations: IR, immediate-release; CR, controlled-release.

separated on an Eclipse XDB-C18 column $(3.0 \times 100 \mathrm{~mm}$, $3.5 \mu \mathrm{m}$; Agilent Technologies) and detected using the positive electrospray ionization and multiple reaction monitoring modes. The mobile phase consisted of $0.2 \%$ formic acid in $5 \mathrm{mM}$ ammonium formate and acetonitrile $(40: 60, \mathrm{v} / \mathrm{v})$, and the flow rate was $0.35 \mathrm{~mL} / \mathrm{min}$. The lower limit of quantification (LLOQ) was $5 \mathrm{ng} / \mathrm{mL}$, and the calibration curve for levodropropizine was linear over the range of $5-1,000 \mathrm{ng} / \mathrm{mL}$ with a coefficient of determination of $\geq 0.99$. The intraday and interday precision were $\leq 3.6$ and $\leq 6.7 \%$, respectively. The intraday and interday accuracy ranged from 95.3 to $103.5 \%$ and 98.2 to $99.2 \%$, respectively.

\section{PKs and statistical analysis}

The PK parameters were calculated through a noncompartmental analysis using Phoenix ${ }^{\circledR}$ WinNonlin ${ }^{\circledR}$ software version 1.4 (Certara, St Louis, MO, USA). To compare the total exposure to levodropropizine $\mathrm{CR}$ and IR, the maximum plasma concentration $\left(C_{\max }\right)$ and area under the concentration-time curve from the 0 to $24 \mathrm{~h}$ time points $\left(\mathrm{AUC}_{0-24 \mathrm{~h}}\right)$ were calculated. In addition, to determine the $\mathrm{PK}$ parameters of levodropropizine IR, the $0-6 \mathrm{~h}$ data were used because they represent the data set after the first dose. Similarly, to determine the PK parameters of levodropropizine CR, the $0-12 \mathrm{~h}$ data were used. The following PK parameters were calculated for both levodropropizine IR and CR: $C_{\max }, T_{\max }, \mathrm{AUC}$ from 0 to dose interval time $\left(\mathrm{AUC}_{0-\mathrm{tau}}\right), \mathrm{AUC}$ from 0 to infinity $\left(\mathrm{AUC}_{\mathrm{inf}}\right), t_{1 / 2}$, and apparent clearance $(\mathrm{CL} / \mathrm{F})$. The AUC was calculated using the linear trapezoidal-linear interpolation method. The $T_{\max }$ and $C_{\max }$ were determined directly based on the observed values. The values below the LLOQ prior to the $T_{\max }$ were regarded as 0 , and the values after the $T_{\max }$ were regarded as missing data. No imputations were made for the missing data when calculating PK parameters.

Statistical analyses were performed using $\mathrm{SAS}^{\circledR}$ software version 6.4 (SAS Institute Inc., Cary, NC, USA). A mixedeffects analysis of variance (ANOVA) model was fit by using the natural logarithm-transformed $C_{\max }$ and $\mathrm{AUC}_{0-24 \mathrm{~h}}$. Based on the ANOVA model, PK comparisons between different formulations were assessed by calculating the geometric mean ratio (GMR) and $90 \%$ confidence interval $(90 \% \mathrm{CI})$ of levodropropizine CR to IR for the $C_{\max }$ and $\mathrm{AUC}_{0-24 \mathrm{~h}}$. In addition, to evaluate the food effect on the PK of levodropropizine $\mathrm{CR}$, the GMR and $90 \% \mathrm{CI}$ of the fed group to the fasted group for the $\mathrm{C}_{\text {max }}$ and $\mathrm{AUC}_{0-24 \mathrm{~h}}$ were calculated. Furthermore, the GMR and $90 \% \mathrm{CI}$ of $\mathrm{AUC}_{0 \text {-tau }} / \mathrm{D}$ and $\mathrm{AUC}_{\text {inf }} / \mathrm{D}$ were calculated. The ANOVA test was used to determine the statistical difference in demographic baseline between six sequences.

\section{Tolerability assessment}

Tolerability was evaluated in all subjects who received at least one dose of the study drug throughout the entire study period. Tolerability was evaluated based on the assessment of the vital signs (blood pressure, heart rate, and body temperature), physical examination, 12-lead electrocardiogram, clinical laboratory tests (hematology, blood chemistry, and urinalysis), and adverse events (AEs).

\section{Results \\ Demographics}

Forty-eight subjects were enrolled in this study, and one subject dropped out because of consent withdrawal. The remaining 47 subjects completed the study as planned and were included in the PK analysis set. The 
Table I $C_{\max }$ and $A \cup C_{0-24 h}$ of levodropropizine in each treatment regimen

\begin{tabular}{|c|c|c|c|c|c|}
\hline \multirow{2}{*}{$\begin{array}{l}\text { Pharmacokinetic } \\
\text { parameters }\end{array}$} & \multirow{2}{*}{$\begin{array}{l}\text { Levodropropizine } \\
\text { IR } 60 \mathrm{mg} \\
\text { Fasted }(\mathrm{n}=47)\end{array}$} & \multicolumn{2}{|c|}{ Levodropropizine CR 90 mg } & \multicolumn{2}{|l|}{ Geometric mean ratio } \\
\hline & & Fasted $(n=47)$ & Fed $(n=47)$ & $\begin{array}{l}\text { Levodropropizine } \\
\text { CR/IR ratio }(90 \% \mathrm{Cl})\end{array}$ & $\begin{array}{l}\text { Levodropropizine CR } \\
\text { fed/fasted ratio }(90 \% \mathrm{Cl})\end{array}$ \\
\hline$C_{\max }(\mu g / L)$ & $325.46 \pm 104.51$ & $261.22 \pm 86.18$ & $237.54 \pm 87.59$ & $0.80(0.75-0.85)$ & $0.90(0.85-0.97)$ \\
\hline $\mathrm{AUC}_{0-24 \mathrm{~h}}(\mathrm{~h} \cdot \mu \mathrm{g} / \mathrm{L})$ & $2,807.73 \pm 1,247.77$ & $2,548.90 \pm 1,182.66$ & $2,712.34 \pm 1,135.10$ & $0.89(0.86-0.93)$ & $1.10(1.05-1.14)$ \\
\hline
\end{tabular}

Notes: Data are presented as arithmetic mean \pm standard deviation. $C_{\text {max }}$, maximum drug concentration; $A \cup C_{0-24 h}$, area under the concentration-time curve from the 0 to $24 \mathrm{~h}$ time point.

Abbreviations: IR, immediate-release; $\mathrm{CR}$, controlled-release; $90 \% \mathrm{Cl}, 90 \%$ confidence interval.

mean \pm standard deviation values of the demographic characteristics of the enrolled subjects were as follows: age, $24.44 \pm 1.63$ years; height, $175.98 \pm 6.60 \mathrm{~cm}$; and body weight, $64.94 \pm 8.54 \mathrm{~kg}$. There were no statistically significant differences in demographic characteristics between six-sequence groups (Table S1).

\section{PK results}

\section{PK characteristics of levodropropizine CR formulation}

The $\mathrm{AUC}_{0-24 \mathrm{~h}}$, which represents the total daily exposure, was similar for both formulations (Table 1). The GMR and $90 \% \mathrm{CI}$ for the $\mathrm{AUC}_{0-24 \mathrm{~h}}$ of levodropropizine $\mathrm{CR}$ to IR were within the conventional bioequivalence range. Levodropropizine $\mathrm{CR}$ showed delayed $T_{\max }$, prolonged $t_{1 / 2}$, and lower $C_{\max }$ compared to that of levodropropizine IR (Figure 2, Tables 1 and 2). The median $T_{\max }$ values were 1.00 and $0.75 \mathrm{~h}$, the mean $t_{1 / 2}$ values were 3.10 and $2.30 \mathrm{~h}$, and the mean $C_{\max }$ values during $24 \mathrm{~h}$ were 261.22 and $325.46 \mu \mathrm{g} / \mathrm{L}$ for levodropropizine CR and
IR, respectively. The GMRs and $90 \%$ CIs for the $C_{\max }$ and dose-normalized $\mathrm{AUC}_{0 \text {-tau }}$ of levodropropizine $\mathrm{CR}$ to IR were within the conventional bioequivalence range after the first single dose administration (Table 2). Individual comparisons of the $C_{\max }$ and $\mathrm{AUC}_{0-24 \mathrm{~h}}$ between levodropropizine $\mathrm{CR}$ and IR are shown in Figure 3.

\section{Food effect on levodropropizine CR}

The total exposure and peak concentration of levodropropizine $\mathrm{CR}$ were similar in both the fasted and fed groups. The GMRs and $90 \%$ CIs for the $C_{\max }$ and $\mathrm{AUC}_{0-24 \mathrm{~h}}$ of levodropropizine $\mathrm{CR}$ fed to the fasted groups were within the conventional bioequivalence range (Table 1). In addition, the GMRs and $90 \%$ CIs for the $C_{\max }$ and dose-normalized $\mathrm{AUC}_{0 \text {-tau }}$ of levodropropizine CR fed to the fasted groups were within the conventional bioequivalence acceptance range (Table 2). The fed group showed delayed absorption compared to the fasted group, and the median $T_{\max }$ values were 3.00 and $1.00 \mathrm{~h}$, respectively (Figure 4 and Table 2).
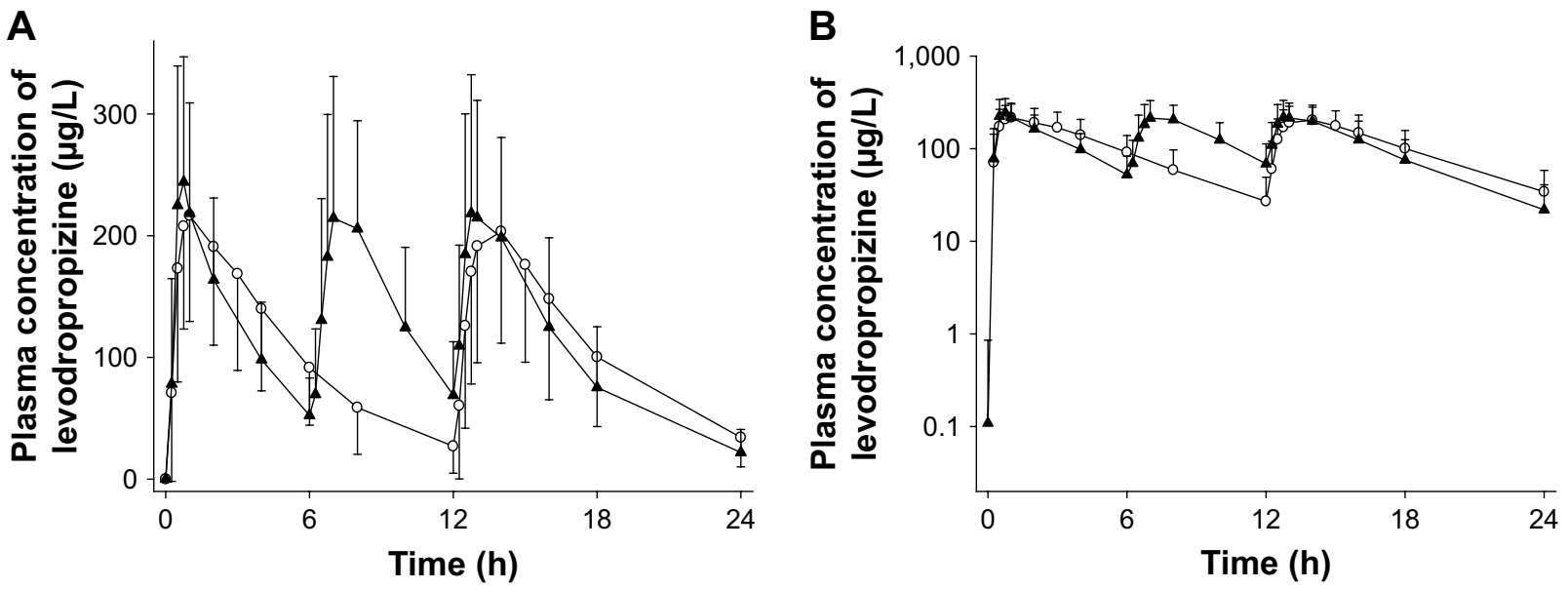

$\multimap-$ Levodropropizine CR $(n=47) \quad \_$Levodropropizine IR $(n=47)$

Figure 2 Mean plasma concentration-time profiles of levodropropizine (A) in linear scale and (B) in log scale following administration of levodropropizine CR 90 mg and IR $60 \mathrm{mg}$ under the fasted state.

Notes: Bars represent standard deviations. Levodropropizine CR was administered twice with I2-h interval, and levodropropizine IR was administered three times with 6-h intervals.

Abbreviations: CR, controlled-release; IR, immediate-release. 
Table 2 Single-dose PK parameters of levodropropizine

\begin{tabular}{|c|c|c|c|c|c|}
\hline \multirow{2}{*}{$\begin{array}{l}\text { Pharmacokinetic } \\
\text { parameter }\end{array}$} & \multirow{2}{*}{$\begin{array}{l}\text { Levodropropizine } \\
\text { IR } 60 \mathrm{mg} \\
\text { Fasted }(\mathrm{n}=46)\end{array}$} & \multicolumn{2}{|c|}{ Levodropropizine CR 90 mg } & \multicolumn{2}{|l|}{ Geometric mean ratio } \\
\hline & & Fasted $(n=47)$ & Fed $(n=46)$ & $\begin{array}{l}\text { Levodropropizine } \\
\text { CR/IR ratio }(90 \% \mathrm{CI})\end{array}$ & $\begin{array}{l}\text { Levodropropizine } \mathrm{CR} \\
\text { fed/fasted ratio }(90 \% \mathrm{Cl})\end{array}$ \\
\hline$T_{\max }(\mathrm{h})$ & $0.75[0.25-2.00]$ & $1.00[0.25-4.00]$ & $3.00[0.25-6.00]$ & - & - \\
\hline$C_{\max }(\mu g / L)$ & $278.14 \pm 100.95$ & $247.99 \pm 81.63$ & $225.46 \pm 84.27$ & $0.89(0.84-0.95)$ & $0.89(0.84-0.95)$ \\
\hline $\mathrm{AUC}_{0-\text { tau }}(\mathrm{h} \cdot \mu \mathrm{g} / \mathrm{L})$ & $774.32 \pm 302.52$ & $1,229.20 \pm 543.16$ & $1,292.76 \pm 545.98$ & - & - \\
\hline $\mathrm{AUC}_{0-\mathrm{tau}} / \mathrm{D}(\mathrm{h} \cdot \mu \mathrm{g} / \mathrm{L} / \mathrm{mg})$ & $12.9 \mid \pm 5.04$ & $13.66 \pm 6.04$ & $14.36 \pm 6.07$ & $1.02(0.98-1.07)$ & $1.07(1.03-1.11)$ \\
\hline$A \cup C_{\text {inf }}(h \cdot \mu g / L)$ & $969.06 \pm 434.06$ & I,37I. $.47 \pm 688.30$ & $\mathrm{I}, 473.83 \pm 657.09$ & - & - \\
\hline $\mathrm{AUC}_{\text {inf }} / \mathrm{D}(\mathrm{h} \cdot \mu \mathrm{g} / \mathrm{L} / \mathrm{mg})$ & $16.15 \pm 7.23$ & $15.24 \pm 7.65$ & $16.38 \pm 7.30$ & $0.92(0.88-0.95)$ & $1.10(1.05-1.15)$ \\
\hline$t_{1 / 2}(\mathrm{~h})$ & $2.30 \pm 0.55$ & $3.10 \pm 0.85$ & $2.85 \pm 0.90$ & - & - \\
\hline CL/F (L/h) & $75.36 \pm 33.91$ & $84.61 \pm 45.10$ & $74.14 \pm 33.94$ & - & - \\
\hline
\end{tabular}

Notes: Data are presented as arithmetic mean \pm standard deviation, except for $T_{\max }$ that is expressed as the median [minimum-maximum]. $C_{\max }$, maximum plasma concentration; $T_{\max }$, time to reach $C_{\max } ; A \cup C_{0-\text { tau }}$, area under the concentration-time curve from 0 to dose interval time; $A U C_{0-\text { tau }} / D$, dose-normalized $A U C_{0-\text { tau }} ; A \cup C_{\text {inf }}$ AUC from 0 to infinity; $A \cup C_{\text {inf }} / D$, dose-normalized $A \cup C_{\text {inf }} ; t_{1 / 2}$, half-life; $C L / F$, apparent clearance.

Abbreviations: PK, pharmacokinetic; IR, immediate-release; CR, controlled-release; $90 \% \mathrm{Cl}$, $90 \%$ confidence interval.

Individual comparisons of the $C_{\max }$ and $\mathrm{AUC}_{0-24 \mathrm{~h}}$ are shown in Figure 5.

\section{Tolerability assessment}

Sixteen AEs occurred in 14 subjects. Of these, five AEs were observed in the levodropropizine IR $60 \mathrm{mg}$ group, and 11 in the levodropropizine CR $90 \mathrm{mg}$ group. All AEs were mild in severity, except for one subject who experienced urticaria after test drug. The AEs that occurred in the levodropropizine CR $90 \mathrm{mg}$ group were the foreign body, dizziness, headache, presyncope, and abrasion. In the levodropropizine IR $60 \mathrm{mg}$ group, diarrhea, rash pustular, pain in extremity, dizziness, headache, pyuria, contusion, dermatitis atopic, pruritus, and urticaria occurred as AEs. Of these, dizziness, headache, and diarrhea were reported as frequent AEs of levodropropizine on the drug label. No serious AEs occurred in either levodropropizine CR or IR administrated group. In addition, there were no clinically significant changes from the baseline of vital signs, physical examinations, electrocardiogram, and clinical laboratory tests in all subjects.

\section{Discussion}

In this study, we aimed to compare the total daily exposure to levodropropizine CR and IR formulations at equal total daily dose of levodropropizine. Therefore, we measured the $C_{\max }$ and $\mathrm{AUC}_{0-24 \mathrm{~h}}$ as primary $\mathrm{PK}$ parameters to compare
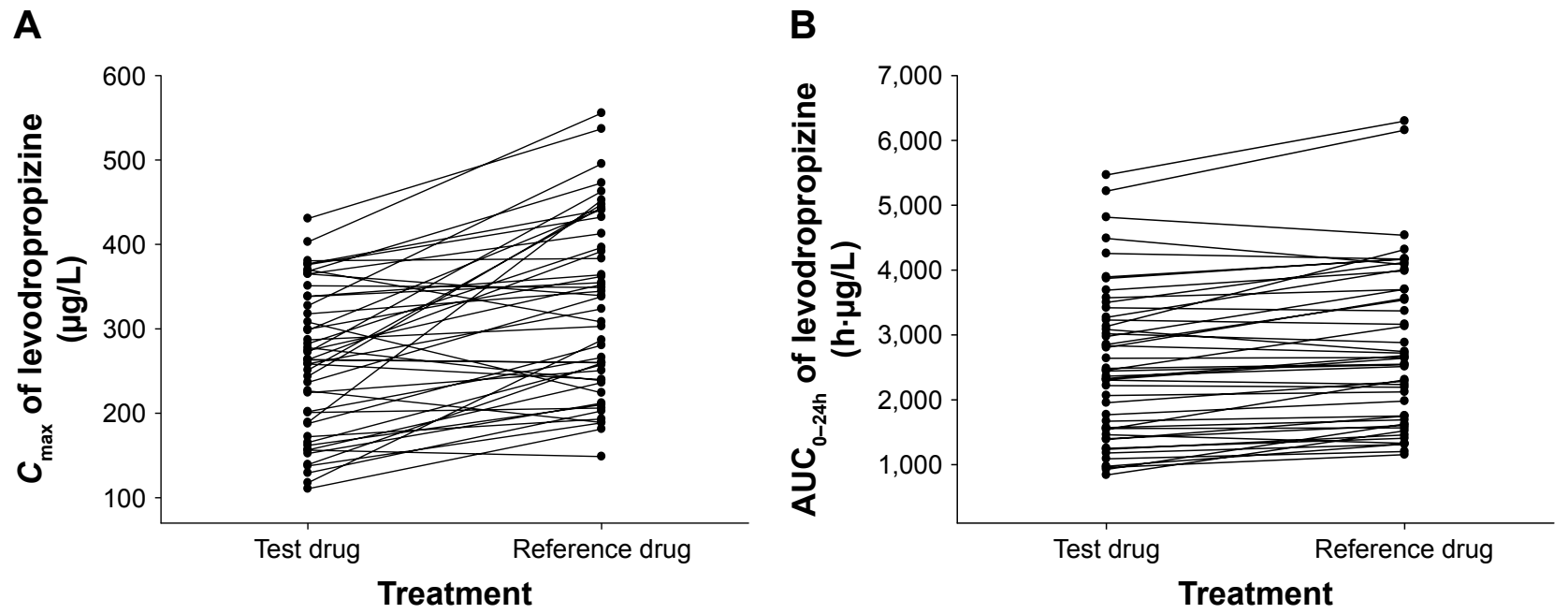

Figure 3 Individual comparisons of $(\mathbf{A}) C_{\max }$ and $(\mathbf{B}) \mathrm{AUC}_{0-24 \mathrm{~h}}$ between the test and reference drugs in the fasted state.

Notes: Subjects received the reference drug three times with 6-h intervals under the fasted state, and received the test drug two times with I2-h interval under the fasted state. Test drug, levodropropizine CR 90 mg; reference drug, levodropropizine IR $60 \mathrm{mg}$; $C_{\text {max }}$, maximum plasma concentration; $A U C_{0-24 h}$, area under the concentration-time curve from the 0 to $24 \mathrm{~h}$ time point.

Abbreviations: $C R$, controlled-release; IR, immediate-release. 

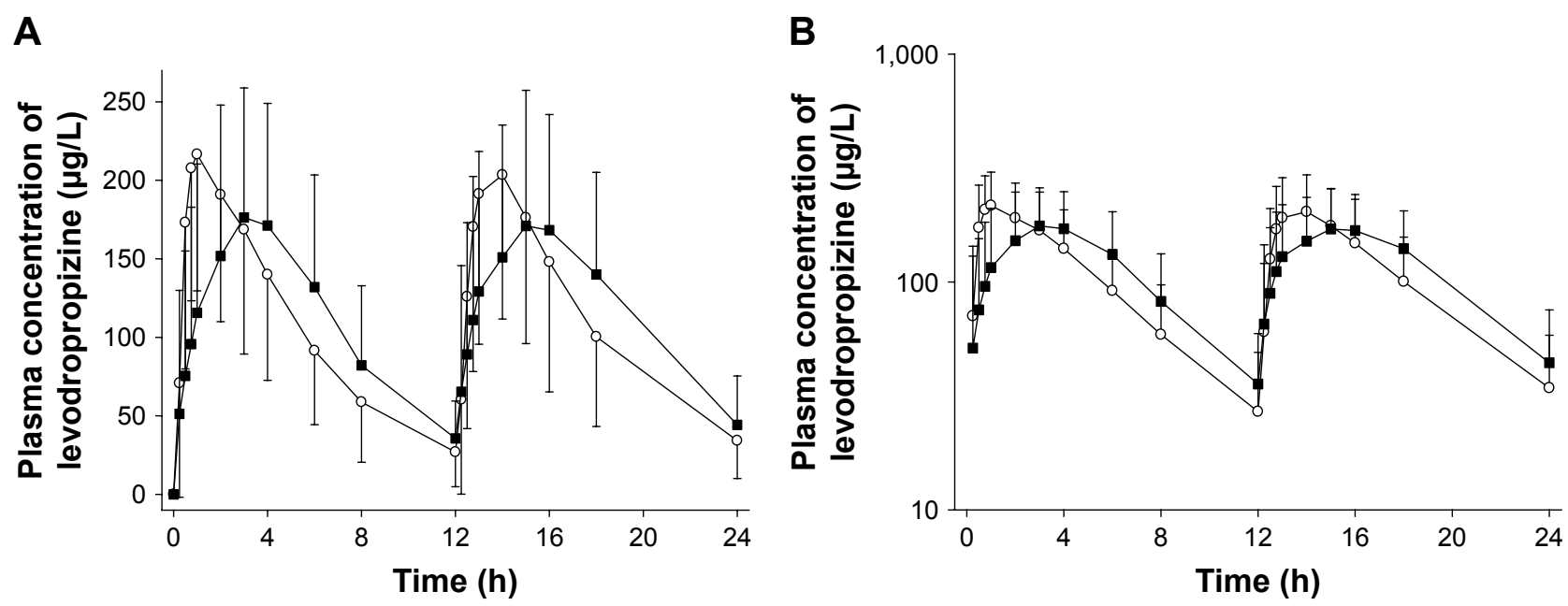

$\multimap-$ Fasted state $(n=47) \rightarrow-$ Fed state $(n=47)$

Figure 4 Mean plasma concentration-time profiles of levodropropizine (A) in linear scale and (B) in log scale following administration of levodropropizine CR 90 mg in the fasted and fed states.

Notes: Bars represent standard deviations. Levodropropizine CR was administered two times with I2-h interval.

Abbreviation: $\mathrm{CR}$, controlled-release.

the PK characteristics of the two formulations. In addition, we calculated the single-dose PK parameters to compare the absorption and elimination profiles of the different formulations.

This study showed that at equal total daily dose, the total daily systemic exposure to levodropropizine was comparable between the CR and IR formulations. The GMR $(90 \% \mathrm{CI})$ of $\mathrm{AUC}_{0-24 \mathrm{~h}}$ was $0.89(0.86-0.93)$ although the GMR $(90 \% \mathrm{CI})$ of $C_{\max }$ was $0.80(0.75-0.85)$. The PK differences between the $90 \mathrm{mg} \mathrm{CR}$ and $60 \mathrm{mg}$ IR tablets might not be clinically significant if the efficacy of levodropropizine is dependent on the total daily systemic exposure. Based on the results of a previous study, the onset of cough inhibitory action of levodropropizine was $1 \mathrm{~h}$ post-dose. ${ }^{14}$ Therefore, a minimal delay in $T_{\max }$ with the CR formulation would be clinically insignificant regarding the onset time of levodropropizine action. Further clinical study will be needed to evaluate the efficacy and safety of the CR formulation compared to the IR formulation.

The US Food and Drug Administration guidance recommends conducting a food-effect study to evaluate the
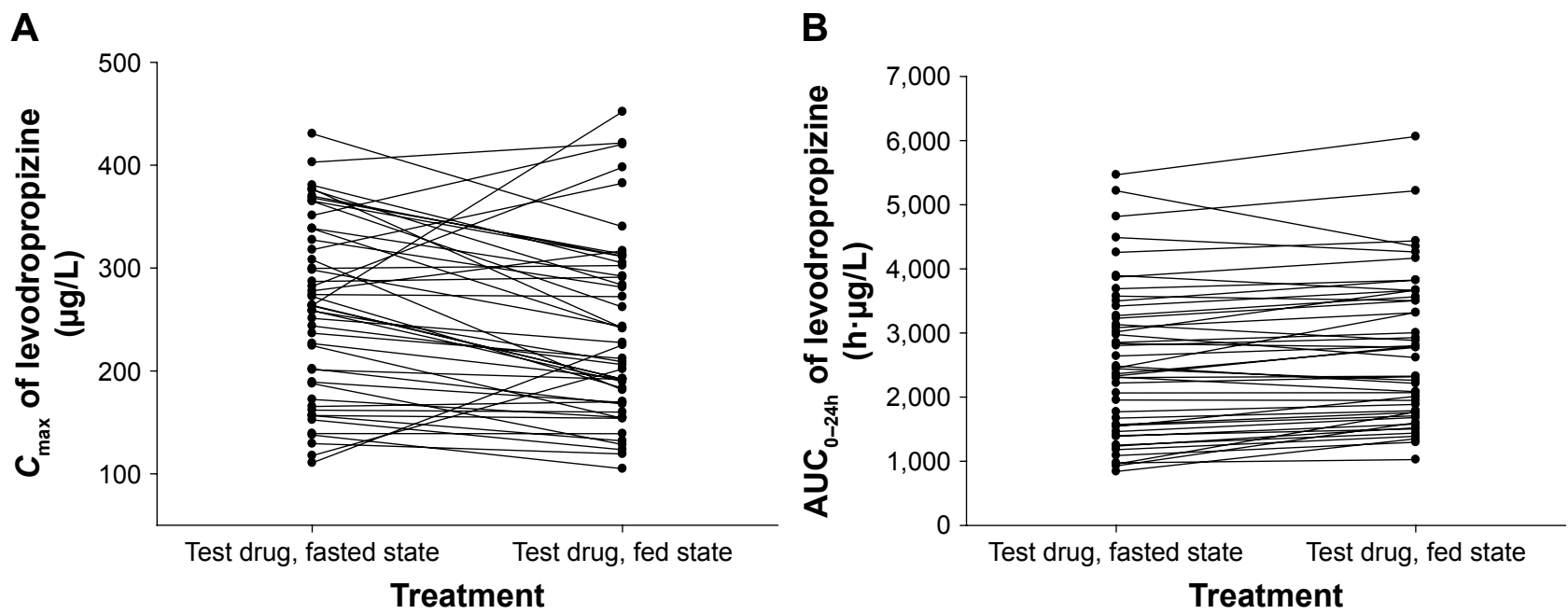

Figure 5 Individual comparisons of $(\mathbf{A}) C_{\max }$ and $(\mathbf{B}) \mathrm{AUC}_{0-24 \mathrm{~h}}$ of the test drug under the fasted and fed states.

Notes: Subjects received the test drug two times with 12 -h interval either in the fasted state or in the fed state. Test drug, levodropropizine $C R \quad 90$ mg; $C_{\text {max }}$, maximum plasma concentration; $\mathrm{AUC}_{0-24 \mathrm{~h}}$, area under the concentration-time curve from the 0 to $24 \mathrm{~h}$ time point.

Abbreviation: $\mathrm{CR}$, controlled-release. 
bioavailability of modified-release formulations. ${ }^{9}$ This is because food can affect the PK of drug in various ways. In this study, food delayed the $T_{\max }$ of levodropropizine CR formulation. This could be attributed to alteration of the gastric $\mathrm{pH}$ because of food intake. For instance, weakly basic drugs, such as levodropropizine ( $\mathrm{p} K_{\mathrm{a} 1}=7.12$ and $\left.\mathrm{p} K_{\mathrm{a} 2}=10.58\right)$, generally exhibit reduced dissolution at high $\mathrm{pH} .{ }^{7,15,16}$ Because the gastric $\mathrm{pH}$ can easily increase by food intake, this can result in decreased absorption rate of weakly basic drugs. In addition, food delays the gastric emptying time, which leads to delayed oral absorption of drugs. ${ }^{17}$ Moreover, food can affect the action of hydroxypropyl methylcellulose (HPMC), which constitutes the matrix that modulates the drug release. For example, HPMC release was more rapid when the $\mathrm{pH}$ condition was similar to the fasted state of the stomach. However, when the $\mathrm{pH}$ increased from 1.20 to 6.80 , it showed slow dissolution. Since the $\mathrm{pH}$ of the stomach after food intake is 4.90 , HPMC would dissolve faster in the fasted state compared to that in the fed state. ${ }^{18}$ These mechanisms might contribute to the delay in $T_{\max }$ of levodropropizine CR when it was administered in the fed state. However, the GMRs and $90 \%$ CIs of the $C_{\max }$ and $\mathrm{AUC}_{0-24 \mathrm{~h}}$ were within the conventional bioequivalence range; thus, the effect of food on the bioavailability of levodropropizine CR would be minimal.

\section{Conclusion}

The total systemic exposure to levodropropizine was comparable between the CR and IR formulations in terms of the AUC. Although food delayed the absorption of levodropropizine CR, systemic exposure was not affected. Both levodropropizine CR and IR formulations were well tolerated in healthy subjects.

\section{Acknowledgments}

This research was supported by a grant of the Korea Health Technology R\&D Project through the Korea Health Industry Development Institute (KHIDI), funded by the Ministry of Health \& Welfare, Republic of Korea (grant numbers: HI14C1063 and HI14C1069). This work was supported by research fund of Chungnam National University.

\section{Disclosure}

Kyu-Yeol Nam, Sang-Min Cho and Youn-Woong Choi are employees of Korea United Pharm Inc., Seoul, Republic of Korea. The authors report no other conflicts of interest in this work.

\section{References}

1. Dicpinigaitis PV, Morice AH, Birring SS, et al. Antitussive drugs - past, present, and future. Pharmacol Rev. 2014;66(2):468-512.

2. Bolser DC. Cough suppressant and pharmacologic protussive therapy: ACCP evidence-based clinical practice guidelines. Chest. 2006; 129(1 suppl):238S-249S.

3. Daffonchio L, Clavenna G, Fedele G, et al. Levodropropizine. Drugs Today. 1995;31:299-305.

4. Shams H, Daffonchio L, Scheid P. Effects of levodropropizine on vagal afferent C-fibres in the cat. Br J Pharmacol. 1996;117:853-858.

5. Lavezzo A, Melillo G, Clavenna G, Omini C. Peripheral site of action of levodropropizine in experimentally-induced cough: role of sensory neuropeptides. Pulm Pharmacol. 1992;5:143-147.

6. Jeon S, Lee J, Hong T, et al. Pharmacokinetics and safety of levodropropizine controlled-release tablet after repeated dosing in healthy male volunteers. J Korean Soc Clin Pharmacol Ther. 2013;21:113-119.

7. Narin I, Sarioglan S, Anilanmert B, et al. pKa determinations for montelukast sodium and levodropropizine. J Solution Chem. 2010;39: $1582-1588$.

8. Borsa M, Glavenna G, Ferrari MP, Canali S, Giachetti C, Zanolo G. Linearity of levodropropizine, a new antitussive drug, in the healthy volunteer. Eur J Drug Metab Pharmacokinet. 1991;3:178-184.

9. U.S. Department of Health and Human Services. Food and Drug Administration. Guidance for Industry: Food-Effect Bioavailability and Fed Bioequivalence Studies. FDA, Center for Drug Evaluation and Research (CDER); 2002. Available from: https://www.fda.gov/downloads/Drugs/ GuidanceComplianceRegulatoryInformation/Guidances/UCM070241. pdf. Accessed March 19, 2018.

10. Won CS, Oberlies NH, Paine MF. Mechanisms underlying fooddrug interactions: inhibition of intestinal metabolism and transport. Pharmacol Ther. 2012;136:186-201.

11. Park J-H, Shin Y, Lee S-Y, Lee SI. Antihypertensive drug medication adherence and its affecting factors in South Korea. Int J Cardiol. 2008; 128:392-398.

12. Hong JS, Kang HC. Relationship between oral antihyperglycemic medication adherence and hospitalization, mortality, and healthcare costs in adult ambulatory care patients with type 2 diabetes in South Korea. Med Care. 2011;49:378-384.

13. Coleman CI, Limone B, Sobieraj DM, et al. Dosing frequency and medication adherence in chronic disease. J Manag Care Pharm. 2012;18: $527-539$.

14. Fumagalli G, Cordaro CI, Vanasia M, et al. A comparative study of the antitussive activity of levodropropizine and dropropizine in the citric acid-induced cough model in normal subjects. Drugs Exp Clin Res. 1992; 18:303-309.

15. Batchelor HK. Influence of food on pediatric gastrointestinal drug absorption following oral administration: a review. Children. 2015;2: 244-271.

16. European Pharmacopoeia Commission, Medicines EDftQo, Healthcare. European Pharmacopoeia 5.0. Vol. 1. Renouf Publishing Company Limited; Council of Europe, Strasbourg, France: 2005.

17. Welling PG. Influence of food and diet on gastrointestinal drug absorption: a review. J Pharmacokinet Biopharm. 1977;5:291-334.

18. Guiastrennec B, Söderlind E, Richardson S, Peric A, Bergstrand M. In vitro and in vivo modeling of hydroxypropyl methylcellulose (HPMC) matrix tablet erosion under fasting and postprandial status. Pharm Res. 2017;34:847-859. 


\section{Supplementary material}

Table SI Baseline demographic characteristics of each sequence

\begin{tabular}{|c|c|c|c|c|c|c|c|}
\hline Characteristics & $\begin{array}{l}\text { Sequence } A \\
(n=8)\end{array}$ & $\begin{array}{l}\text { Sequence B } \\
(n=8)\end{array}$ & $\begin{array}{l}\text { Sequence } C \\
(n=8)\end{array}$ & $\begin{array}{l}\text { Sequence D } \\
(n=8)\end{array}$ & $\begin{array}{l}\text { Sequence } E \\
(n=8)\end{array}$ & $\begin{array}{l}\text { Sequence F } \\
(n=8)\end{array}$ & $p$-value \\
\hline Age (years) & $24.13 \pm 1.64$ & $24.75 \pm 1.67$ & $23.50 \pm 1.51$ & $24.38 \pm 1.92$ & $24.50 \pm 2.07$ & $23.88 \pm 1.89$ & 0.7678 \\
\hline Height $(\mathrm{cm})$ & $|7| .38 \pm 6.99$ & $177.38 \pm 5.45$ & $176.75 \pm 6.67$ & $173.88 \pm 5.94$ & $175.63 \pm 5.73$ & $180.88 \pm 6.47$ & 0.0776 \\
\hline Weight (kg) & $65.53 \pm 8.94$ & $66.45 \pm 8.09$ & $66.78 \pm 6.37$ & $62.70 \pm 3.94$ & $67.65 \pm 5.74$ & $73.80 \pm 6.80$ & 0.0609 \\
\hline BMI $\left(\mathrm{kg} / \mathrm{m}^{2}\right)$ & $22.23 \pm 1.73$ & $21.06 \pm 1.69$ & $21.37 \pm 1.60$ & $20.81 \pm 2.12$ & $21.93 \pm 1.55$ & $22.52 \pm 1.19$ & 0.2732 \\
\hline
\end{tabular}

Note: Data are presented as arithmetic mean \pm standard deviation.

Abbreviation: BMI, body mass index.

\section{Publish your work in this journal}

Drug Design, Development and Therapy is an international, peerreviewed open-access journal that spans the spectrum of drug design and development through to clinical applications. Clinical outcomes, patient safety, and programs for the development and effective, safe, and sustained use of medicines are the features of the journal, which has also been accepted for indexing on PubMed Central. The manuscript management system is completely online and includes a very quick and fair peer-review system, which is all easy to use. Visit http://www.dovepress.com/testimonials.php to read real quotes from published authors. 